\title{
Child maltreatment in Germany: prevalence rates in the general population
}

\author{
Andreas Witt ${ }^{1^{*}{ }^{\prime}}$, Rebecca C. Brown ${ }^{1 \dagger}$, Paul L. Plener ${ }^{1}$, Elmar Brähler ${ }^{2,3}$ and Jörg M. Fegert ${ }^{1}$
}

\begin{abstract}
Background: Child maltreatment and its consequences are considered a major public health problem. So far, there is only one study from Germany reporting prevalence rates on different types of maltreatment.

Methods: A representative sample of the German general population was examined for experiences of child maltreatment using the Childhood Trauma Questionnaire (CTQ) between September and November 2016. A total of 2510 (53.3\% female) participants between 14 and 94 years ( $M=48.8$ years) were enrolled. Besides the $C T Q$, a range of sociodemographic information was collected. The interrelatedness of different types of maltreatment was examined using configuration analysis and predictors for maltreatment were identified by performing binary logistic regression analyses.
\end{abstract}

Results: Overall, 2.6\% (f: 3.9\%, m: 1.2\%) of all participants reported severe emotional abuse, 3.3\% (f: 3.4\%, m: 3.3\%) severe physical abuse, 2.3\% (f: 3.7\%, m: 0.7\%) severe sexual abuse, $7.1 \%$ (f: 8.1\%, m: 5.9\%) severe emotional neglect and 9\% (f: 9.2\%, m: 8.9\%) severe physical neglect. Women were more likely to report at least moderate sexual and emotional abuse than men. The largest difference between age groups was reported for physical neglect, with participants aged over 70 years reporting the highest rates. Participants who reported childhood maltreatment were more likely to be unemployed or have lower educational outcomes. The most common combination of maltreatment types were physical and emotional neglect, all five types of maltreatment combined and physical and emotional neglect and physical abuse combined.

Conclusions: Child maltreatment, especially physical neglect is common in the German population. Women seem to be at greater risk for sexual and emotional abuse than men. Knowledge about different types of maltreatment based on the Childhood Trauma Questionnaire (CTQ) can help to put findings of future studies into an epidemiological and societal context.

Keywords: Prevalence, Child maltreatment, Child abuse and neglect, Representative study

\section{Background}

Child maltreatment is considered a major public health problem [1-3]. The consequences of maltreatment are diverse and may affect victims throughout their whole lifespan via psychological and behavioral problems, as well as somatic disorders [1, 4-11]. As a consequence, in addition to these individual consequences, maltreatment causes high financial burden for society. Previous

\footnotetext{
*Correspondence: Andreas.Witt@uniklinik-ulm.de

${ }^{\dagger}$ Andreas Witt and Rebecca C. Brown contributed equally to this work

${ }^{1}$ Department of Child and Adolescent Psychiatry/Psychotherapy,

University of Ulm, Steinhövelstr. 5, 89073 Ulm, Germany

Full list of author information is available at the end of the article
}

studies estimated annual expenses caused by maltreatment between 11 to 30 billion Euros for Germany [7] and up to 124 billion US Dollars per year in the US [8].

Results from international studies show that child maltreatment is highly prevalent. This is also true in high income countries where prevalence rates are comparable to those of widespread diseases $[9,10]$. Meta-analyses on the prevalence of different types of maltreatment exist, and especially child sexual abuse having been reviewed repeatedly [10-13]. One meta-analyses showed varying prevalence rates mostly due to varying definitions, but also due to methodological factors, like small sample sizes, geographical regions or non-random designs 
$[11,13]$. One review by Stoltenborgh and colleagues [11] focused on the assessment of child sexual abuse in adult populations and included 331 independent samples with a total of almost 10 million participants. The overall prevalence for self-reported child sexual abuse was reported at around $12.7 \%$ ( $95 \%$ confidence interval (CI) $10.7-15.0 \%), 18 \%$ for women and $7.6 \%$ for men. These rates are comparable to those found in other meta-analyses $[10,12]$ and also in a meta-analysis focusing on prevalence rates of sexual abuse in adolescent populations [13]. Overall, females seem to be more often affected by sexual abuse than men.

For other types of maltreatment like neglect, the data base is less comprehensive. The so-called "neglect of neglect" is still evident in research [3, 14, 15]. Metaanalyses on physical and emotional abuse, as well as neglect show a high variation in prevalence rates [15-17]. Regarding physical abuse, prevalence rates of $22.6 \%$ (95\% CI 19.6-26.1\%) were reported by Stoltenborgh and colleagues [16], similar to $22.9 \%$ by Sethi and colleagues for the European Region [10]. Larger differences were reported for emotional abuse with a rate of $36.3 \%$ worldwide [17] and 29.1\% reported from the European Union [10]. With regard to child neglect, Stoltenborgh and colleagues identified 19 independent samples, underlining the need for further studies on neglect. Prevalence rates were reported at $16.3 \%$ (95\% CI 12.1-21.5) for physical and $18.4 \%$ (95\% CI 13.0-25.4) for emotional neglect. In contrast to findings on sexual abuse, there does not seem to be a gender preponderance for the other types of maltreatment $[3,15-17]$.

For Germany, data on the prevalence of child maltreatment in the general population is limited to three data sets: two studies, which were conducted almost 20 years apart from each other, focused on the assessment of child sexual abuse [18-20]. They reported a marked decline of sexual abuse over a period of almost 20 years. Only one study reported on the prevalence of different types of maltreatment in the general population. The study was conducted in 2010 using the Childhood Trauma Questionnaire (CTQ) [21, 22] and reported a prevalence of $1.6 \%$ for severe emotional, $2.8 \%$ for severe physical, $1.9 \%$ for severe sexual abuse, and $6.6 \%$ for severe emotional and $10.8 \%$ for severe physical neglect [22].

In summary, data on the prevalence of different types of child maltreatment exist, however usually only general prevalence rates for different types of maltreatment and males and females are reported. On closer examination, prevalence rates vary considerably across different subgroups (e.g. age cohorts or gender) [18, 22]. As the CTQ has been used in a range of brain imaging studies as a covariate $[23,24]$ and it is a widely used screening instrument for the assessment of child maltreatment [22, $25,26]$ recent data need to be made available to set new scientific findings into context and inform the debate of societal burden by childhood maltreatment.

The aim of the present study is to provide recent and detailed prevalence rates for all types of maltreatment as assessed by the CTQ (emotional, physical, and sexual abuse, as well as physical and emotional neglect) in a representative sample of the general population in Germany.

\section{Methods \\ Procedure}

Data collection took place between September and November 2016. Using a random route procedure, a representative sample of the German population was obtained by a demographic consulting company (USUMA, Berlin, Germany). The sample was representative in regard to age, gender, and geographic region. Households of every third residence in a randomly chosen street were invited to participate in the study. In multi-person households, participants were randomly selected using a Kish-Selection-Grid. For inclusion, participants had to be at least 14 years of age and have sufficient German language skills. Of 4902 designated addresses, 2510 households participated in the study. The main reason for non-participation was failure to contact anyone in the residence after four attempts (14.9\%), refusal by the individual who answered the door to have anyone in the household participate in the study (15.3\%), failure to contact the randomly selected household member after four attempts (2.3\%) and refusal by the selected member to participate (14.7\%).

Individuals who agreed to participate were given information about the study and provided informed consent. Participants were told that the study was about psychological health and well-being. Responses were anonymous. In a first step, socio-demographic information was obtained in an interview-format by the research staff. Then, the researcher handed out a copy of the questionnaire and a sealable envelope. The researcher remained nearby in case the participants needed further information. The completed questionnaires were linked to the respondent's demographic data, but did not contain name, address, or any other identifying information.

The study was conducted in accordance with the Declaration of Helsinki, and fulfilled the ethical guidelines of the International Code of Marketing and Social Research Practice of the International Chamber of Commerce and of the European Society of Opinion and Marketing Research. The study was approved by the Ethics Committee of the Medical Department of the University of Leipzig. 


\section{Measures}

The sociodemographic section contained information on age, gender, citizenship, geographical area (East vs. West Germany, rural vs. urban area), educational and occupational status and partnership status. Additionally, an estimation of the equivalence income (household income divided by the square root of household size), according to OECD [27] was calculated.

The prevalence of five types of child maltreatment was assessed using the 28 item brief version of the Childhood Trauma Questionnaire (CTQ) [21, 28, 29]. The CTQ is a screening measure for the assessment of child maltreatment. The CTQ contains five subscales each assessed by 5 items, including sexual, emotional and physical abuse as well as emotional and physical neglect. Additionally, three items assess whether participants tend to minimize problematic experiences within their family. The psychometric properties of the German version of the CTQ have been demonstrated by Klinitzke and colleagues [21]. The internal consistency ranged between 0.62 and 0.96 for the subscales. The intra-class coefficient for an interval of
6 weeks was 0.77 for the overall scale and for subscales between 0.58 and 0.81 . Based on norm data by Häuser and colleagues [22] severity scores for each subscale can be calculated, ranging from "none-minimal", "minimalmoderate", "moderate-severe", to "severe-extreme". For the prevalence analysis of the different types of maltreatment, a cut-off of at least "moderate-severe" was chosen.

\section{Participants}

A total of 2510 participants were included in the sample. Participants were on average 48.4 years old $(\mathrm{SD}=18.2)$ and $53.3 \%$ were female. $3.2 \%$ reported a place of birth outside Germany. The sample was representative for the German population in regard to age and gender. The sociodemographic characteristics are presented in Table 1.

\section{Statistical analyses}

All analyses were conducted using SPSS version 21. Descriptive analyses were conducted for prevalence rates. Comparisons were conducted using $\chi^{2}$ tests. To

Table 1 Demographic data

\begin{tabular}{|c|c|c|c|}
\hline & Total $(\mathrm{N}=2510)$ & Female $(\mathrm{N}=1339)$ & Male $(\mathrm{N}=1171)$ \\
\hline \multicolumn{4}{|l|}{ Age } \\
\hline Mean (standard deviation) & $48.4(18.2)$ & $48.9(18.1)$ & $47.8(18.4)$ \\
\hline Range & $14-94$ & $14-94$ & $14-93$ \\
\hline \multicolumn{4}{|l|}{ Living with partner } \\
\hline Yes & $1370(55 \%)$ & $719(54 \%)$ & $651(56.2 \%)$ \\
\hline No & $1119(45 \%)$ & $612(46 \%)$ & $507(43.8 \%)$ \\
\hline \multicolumn{4}{|l|}{ Citizenship } \\
\hline German & 2429 (96.8\%) & $1303(97.3 \%)$ & $1126(96.2 \%)$ \\
\hline Not German & $81(3.2 \%)$ & $36(2.7 \%)$ & $45(3.8 \%)$ \\
\hline \multicolumn{4}{|l|}{ Geographical area } \\
\hline Eastern Germany & $505(20.1 \%)$ & $255(19 \%)$ & $921(78.7 \%)$ \\
\hline Western Germany & 2005 (79.9\%) & $1084(81 \%)$ & $250(21.3 \%)$ \\
\hline Rural & 1026 (40.9\%) & $548(40.9)$ & $478(40.8 \%)$ \\
\hline Urban & $1484(59.1 \%)$ & 791 (59.1\%) & $693(59.2 \%)$ \\
\hline \multicolumn{4}{|l|}{ Occupational status } \\
\hline Full-time & $1074(42.8 \%)$ & $407(30.4 \%)$ & $667(57 \%)$ \\
\hline Part-time & $281(11.2 \%)$ & $246(18.4 \%)$ & $35(3 \%)$ \\
\hline Hourly & $60(2.4 \%)$ & $54(4 \%)$ & $6(0.5 \%)$ \\
\hline Federal volunteer service/parental leave & $25(1 \%)$ & $22(1.6 \%)$ & $3(0.3 \%)$ \\
\hline Unemployed & $131(5.2 \%)$ & $64(4.8 \%)$ & $67(5.7 \%)$ \\
\hline Retiree & $638(25.4 \%)$ & $368(27.5 \%)$ & $270(23.1 \%)$ \\
\hline Homemaker & $79(3.1 \%)$ & $77(5.8 \%)$ & $2(0.2 \%)$ \\
\hline In training & $42(1.7 \%)$ & $21(1.6 \%)$ & $21(1.8 \%)$ \\
\hline Student & $161(6.4 \%)$ & $70(5.2 \%)$ & $91(7.8 \%)$ \\
\hline \multicolumn{4}{|l|}{ Employment status } \\
\hline Unemployed & $131(5.3 \%)$ & $64(4.8 \%)$ & $67(5.8 \%)$ \\
\hline Employed & $2360(94.7 \%)$ & 1265 (95.2\%) & 1095 (94.2\%) \\
\hline
\end{tabular}


assess the co-occurrence of different types of child maltreatment a configuration analysis was conducted. Binary logistic regression analyses were conducted to identify predictors of childhood maltreatment. Age and gender were entered in the analyses as potential predictors.

\section{Results}

Of the $\mathrm{N}=2487$ participants who completed the CTQ, $31.0 \%(\mathrm{n}=772)$ reported at least one type of child maltreatment. Of all participants, $6.5 \%$ reported at least moderate emotional abuse, $6.7 \%$ reported physical abuse, $7.6 \%$ sexual abuse, $13.3 \%$ emotional neglect, and $22.5 \%$ reported physical neglect (for details see Table 2).

\section{Co-morbidity of types of child maltreatment}

Overall, $58.10 \%(\mathrm{~N}=416)$ of those reporting any form of child maltreatment reported only one type of maltreatment. In detail, $47.15 \%(\mathrm{~N}=265)$ of those reporting physical neglect $(\mathrm{N}=562) 31.58 \%(\mathrm{~N}=60$ out of $\mathrm{N}=190$ ) of those reporting sexual abuse, $14.76 \%$ $(\mathrm{N}=49$ out of $\mathrm{N}=332)$ of those reporting emotional neglect, $13.17 \%(\mathrm{~N}=22$ out of $\mathrm{N}=167)$ of those reporting physical abuse, and $12.27 \%(\mathrm{~N}=20$ out of 163$)$ of those reporting emotional abuse did not report another type of maltreatment. The most common combination of types of child maltreatment were physical and emotional neglect (13.99\%), all five types of maltreatment combined
(3.89\%) and physical and emotional neglect and physical abuse combined (3.50\%) (for details see Table 3).

\section{Predictors of moderate to severe types of maltreatment} Gender was shown to be a predictor for emotional and sexual abuse, with women reporting higher rates of both types of abuse (see Table 4; details on gender differences by severity of maltreatment are also presented in Table 2). Furthermore, age was identified as a predictor for physical neglect, with higher age being associated with higher prevalence rates (see Table 4; Fig. 1 for details).

\section{Age differences concerning the prevalence of child maltreatment}

The experience of at least one type of child maltreatment was reported most frequently in the oldest age group of $70+(50.4 \%)$ and least often in the youngest age group of 14-19 years olds (13.4\%). Participants aged between 20 and 69 years reported rather consistent rates of 24.3-33.8\% (for details see Fig. 1). The largest difference between age groups was reported for physical neglect, with participants aged over 70 years reported much higher rates $(46 \%)$ than participants of other age groups (for details see Fig. 1).

Regarding child abuse, highest rates of emotional and sexual abuse were reported in the age group of $40-49$ year olds. Rates of childhood physical abuse were

Table 2 Prevalence of child maltreatment by severity

\begin{tabular}{|c|c|c|c|c|c|}
\hline & $\mathbf{N}$ & $\begin{array}{l}\text { None-minimal } \\
\mathrm{N}(\%)\end{array}$ & $\begin{array}{l}\text { Low-moderate } \\
\mathrm{N}(\%)\end{array}$ & $\begin{array}{l}\text { Moderate-severe } \\
\text { N (\%) }\end{array}$ & $\begin{array}{l}\text { Severe-extreme } \\
\mathrm{N}(\%)\end{array}$ \\
\hline \multicolumn{6}{|c|}{ Emotional abuse } \\
\hline Total & 2492 & 2027 (80.8) & $302(12.0)$ & $98(3.9)$ & $65(2.6)$ \\
\hline Female & 1324 & $1053(79.5)$ & $156(11.8)$ & $64(4.8)$ & $51(3.9)$ \\
\hline Male & 1168 & $974(83.4)$ & $146(12.5)$ & $34(2.9)$ & $14(1.2)$ \\
\hline \multicolumn{6}{|c|}{ Physical abuse } \\
\hline Total & 2497 & $2185(87.1)$ & $145(5.8)$ & $83(3.3)$ & $84(3.3)$ \\
\hline Female & 1330 & 1165 (87.6) & $79(5.9)$ & $41(3.1)$ & $45(3.4)$ \\
\hline Male & 1167 & $1020(87.4)$ & $66(5.7)$ & $42(3.6)$ & $39(3.3)$ \\
\hline \multicolumn{6}{|c|}{ Sexual abuse } \\
\hline Total & 2496 & $2148(85.6)$ & $158(6.3)$ & $133(5.3)$ & $57(2.3)$ \\
\hline Female & 1329 & $1090(82.0)$ & $89(6.7)$ & $101(7.6)$ & $49(3.7)$ \\
\hline Male & 1167 & $1058(90.7)$ & $69(5.9)$ & $32(2.7)$ & $8(0.7)$ \\
\hline \multicolumn{6}{|c|}{ Emotional neglect } \\
\hline Total & 2496 & $1486(59.2)$ & $678(27.0)$ & $155(6.2)$ & $177(7.1)$ \\
\hline Female & 1329 & $809(60.9)$ & $334(25.1)$ & $78(5.9)$ & $108(8.1)$ \\
\hline Male & 1167 & $677(58.0)$ & $344(29.5)$ & $77(6.6)$ & $69(5.9)$ \\
\hline \multicolumn{6}{|c|}{ Physical neglect } \\
\hline Total & 2496 & $1452(57.8)$ & $482(19.2)$ & $336(13.4)$ & $226(9.0)$ \\
\hline Female & 1329 & $786(59.1)$ & $251(18.9)$ & $170(12.8)$ & $122(9.2)$ \\
\hline Male & 1167 & $666(57.1)$ & 231 (19.8) & $166(14.2)$ & $104(8.9)$ \\
\hline
\end{tabular}


Table 3 Prevalence of different types and combinations of maltreatment

\begin{tabular}{|c|c|c|}
\hline $\begin{array}{l}\text { Type/combination of mal- } \\
\text { treatment }\end{array}$ & $\mathrm{N}$ & $\begin{array}{l}\text { Percent in relation to partici- } \\
\text { pants with at least one type } \\
\text { of maltreatment }(\mathrm{N}=772)\end{array}$ \\
\hline Emotional abuse (EA) only & 20 & 2.59 \\
\hline Physical abuse (PA) only & 22 & 2.85 \\
\hline Sexual abuse (SA) only & 60 & 7.77 \\
\hline Emotional neglect (EN) only & 49 & 6.35 \\
\hline Physical neglect (PN) only & 265 & 34.33 \\
\hline $\mathrm{EA}+\mathrm{PA}$ & 4 & 0.52 \\
\hline$E A+S A$ & 12 & 1.55 \\
\hline$E A+E N$ & 13 & 1.68 \\
\hline$E A+P N$ & 5 & 0.65 \\
\hline$P A+S A$ & 1 & 0.13 \\
\hline $\mathrm{PA}+\mathrm{EN}$ & 3 & 0.39 \\
\hline $\mathrm{PA}+\mathrm{PN}$ & 11 & 1.42 \\
\hline $\mathrm{SA}+\mathrm{EN}$ & 3 & 0.39 \\
\hline$S A+P N$ & 13 & 1.68 \\
\hline$E N+P N$ & 108 & 13.99 \\
\hline$E A+P A+S A$ & 3 & 0.39 \\
\hline $\mathrm{EA}+\mathrm{PA}+\mathrm{EN}$ & 18 & 2.33 \\
\hline$E A+P A+P N$ & 4 & 0.52 \\
\hline$E A+S A+E N$ & 4 & 0.52 \\
\hline$E A+S A+P N$ & 3 & 0.39 \\
\hline$E A+E N+P N$ & 7 & 0.91 \\
\hline$P A+S A+E N$ & 1 & 0.13 \\
\hline$P A+S A+P N$ & 4 & 0.52 \\
\hline$P A+E N+P N$ & 27 & 3.50 \\
\hline$S A+E N+P N$ & 20 & 2.59 \\
\hline $\mathrm{EA}+\mathrm{PA}+\mathrm{SA}+\mathrm{EN}$ & 2 & 0.26 \\
\hline $\mathrm{EA}+\mathrm{PA}+\mathrm{SA}+\mathrm{PN}$ & 10 & 1.30 \\
\hline$E A+P A+E N+P N$ & 21 & 2.72 \\
\hline$E A+S A+E N+P N$ & 6 & 0.78 \\
\hline$P A+S A+E N+P N$ & 14 & 1.81 \\
\hline$E A+P A+S A+E N+P N$ & 30 & 3.89 \\
\hline
\end{tabular}

$E A$ emotional abuse, $P A$ physical abuse, $S A$ sexual abuse, $E N$ emotional neglect, $P N$ physical neglect higher in older age groups than in younger participants (see Fig. 2).

Socio-demographic variables and childhood maltreatment All five types of child maltreatment were analyzed separately regarding different socio-demographic variables (being employed or unemployed, level of education and equivalence income). Participants who were unemployed, had a lower level of education and a lower equivalence income reported highest rates of emotional abuse, physical abuse, and physical and emotional neglect. Sexual abuse was reported more often by unemployed participants (for details see Table 5).

\section{Discussion}

Prevalence rates

The aim of the present study was to provide recent prevalence data on five types of child maltreatment, assessed with the CTQ in the general population in Germany. Detailed prevalence rates are presented separately for 10 age cohorts, gender, different demographic variables and severity. Additionally, co-occurrences of and predictors for different types of maltreatment analysed. The methodology of the present study was identical to the study of Häuser and colleagues [22], who assessed child maltreatment using the CTQ in the general population of Germany. In general, prevalence rates found in the present study again underline that child maltreatment, especially physical neglect, is rather common in the general population of Germany. Overall, rates found by Häuser and colleagues, were replicated [22]. In the current sample $2.6 \%$ reported severe emotional, 3.3\% severe physical and 2.3\% severe sexual abuse. Additionally 7.1\% reported severe emotional and 9\% severe physical neglect. Compared to Häuser and colleagues [22], the rates for all types of maltreatment (except physical neglect, with 10.7), were higher: For severe emotional abuse, they reported a rate of $1.6,2.8 \%$ for physical abuse, $1.9 \%$ for sexual abuse and $6.6 \%$ for emotional neglect. However, those higher

Table 4 Binary logistic regressions for predictors of different types of maltreatment

\begin{tabular}{|c|c|c|c|c|c|}
\hline Dependent variable & Independent variable & Odds ratio (OR) & 95\% confidence interval $(\mathrm{Cl})$ & $\beta$ & $p$ \\
\hline \multirow[t]{2}{*}{ Emotional abuse } & Gender & 0.444 & $0.313-0.629$ & -0.812 & $<.001$ \\
\hline & Age & 0.997 & $0.988-1.006$ & -0.003 & .547 \\
\hline \multirow[t]{2}{*}{ Physical abuse } & Gender & 1.114 & $0.81-1.530$ & 0.108 & .504 \\
\hline & Age & 1.008 & $0.999-1.017$ & 0.008 & .065 \\
\hline \multirow[t]{2}{*}{ Sexual abuse } & Gender & 0.281 & $0.196-0.403$ & -1.269 & $<.001$ \\
\hline & Age & 1.004 & $0.995-1.012$ & 0.004 & .406 \\
\hline \multirow[t]{2}{*}{ Emotional neglect } & Gender & 0.871 & $0.688-1.102$ & -0.139 & .249 \\
\hline & Age & 1.005 & $0.998-1.011$ & 0.005 & .148 \\
\hline \multirow[t]{2}{*}{ Physical neglect } & Gender & 1.103 & $0.908-1.340$ & 0.098 & .325 \\
\hline & Age & 1.027 & $1.021-1.032$ & 0.026 & $<.001$ \\
\hline
\end{tabular}


$60,0 \%$

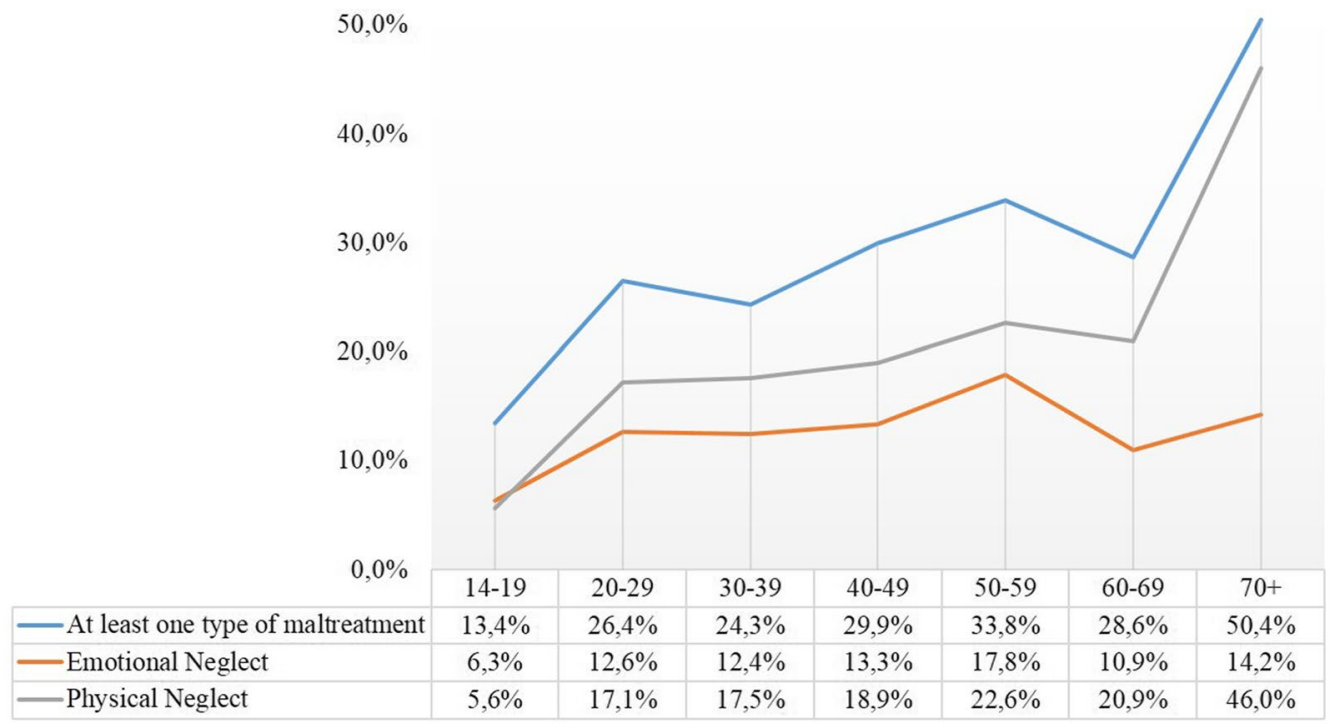

-At least one type of maltreatment

-Emotional Neglect

- Physical Neglect

Fig. 1 Prevalence of child neglect and having experienced at least type of maltreatment divided by age groups

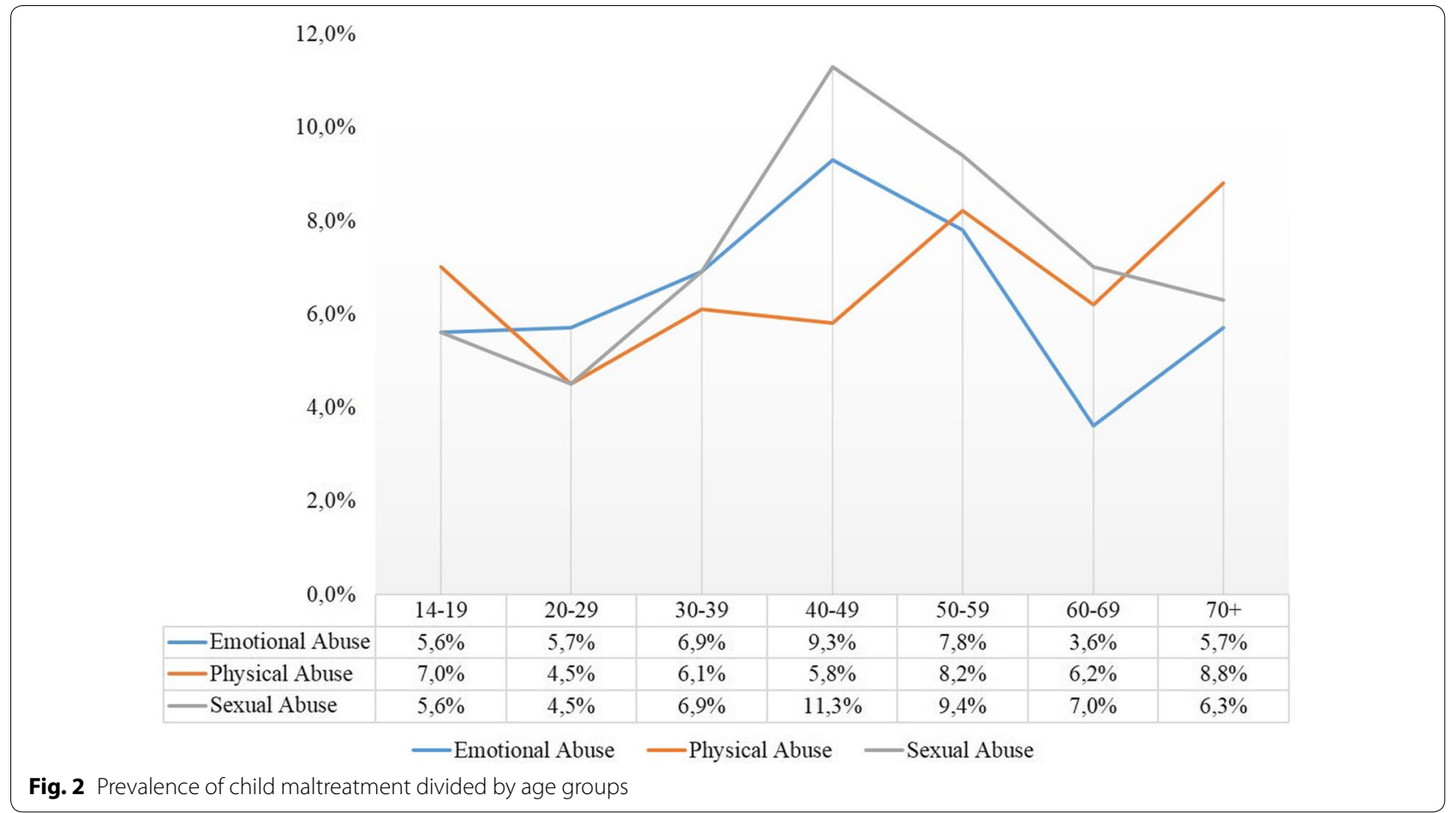

rates might represent statistical variation and have to be examined for statistical significance. An explanation for the rise in prevalence rates may be due to an increased awareness in the general population. In 2010, right at the time, when the data collection of the study of Häuser and colleagues [22] took place, the so called abuse scandals in the Roman Catholic Church and in educational institutions with high reputations [30] came aware to the 
public. In its aftermath a public and political discussion about sexual abuse, but also other types of maltreatment started and a range of measures for intervention and better prevention were taken. This broad discussion might have led to a higher awareness about sexual abuse and child maltreatment in general and might have given rise to reported rates of childhood maltreatment in our study. In contrast the prevalence for physical neglect is smaller in the present study compared to Häuser and colleagues [22].

In comparison to prevalence rates for sexual abuse reported in meta-analyses, the rate of the present study for at least having experienced moderate sexual abuse is rather low [10-12]. The prevalence rate for physical neglect was higher compared to those found by Stoltenborgh and colleagues [15]. Emotional and physical neglect also have been found to be most common type of maltreatment in the US [31].

\section{Comparison of age cohorts}

Older age was a significant predictor of physical neglect. The rates for physical neglect were the highest among those of 70 years and older with about $46 \%$. This generation was born in, or before 1946 and therefore survived World War II and the period after the war. This period was marked by hardship for the population, thus making high rates of physical neglect not astonishing among this particular group. This age group is no longer as strongly represented in the present study as compared to Häuser and colleagues [22] due to demographic changes in the population therefore explaining lower rates of physical neglect in our sample in comparison to this former study.
Although not significantly, rates for physical abuse seemed to be declining from the oldest age cohorts towards the youngest, albeit an increase among the youngest age cohort. This general decrease from the oldest age cohorts towards those between 20 and 29 years might be due to change in norms in the society and the legal ban on physical punishment in Germany in the year 2000 [32, 33], with the higher rates in the youngest age cohort maybe explained by a clearer recall of physical abuse. For emotional and sexual abuse the pattern was quite different. For both types of maltreatment, highest prevalence rates were observed in the age group of 40-49 year olds. Quite interestingly, the present study found a steep increase in prevalence rates for sexual abuse among the age cohorts of 40-49 year olds and 50-59 year olds. However, it remains unclear whether this result represents an actual increase in rates or represents an increase in reporting due to an increased perception of the problem because of changes in social norms. The rates for emotional neglect seemed to be relatively stable across age groups. In general repeated surveys in student populations would be necessary to identify changes over time.

\section{Maltreatment and sociodemographic variables}

Concerning other socio-demographic variables, the results generally show a higher prevalence of different types of maltreatment among those with a lower sociodemographic status. This becomes apparent in education and employment status and consequently in the monthly equivalence income, thus pointing towards the lifelong consequences of maltreatment also on the societal level that have been described in the literature $[1,5,7,8]$.

Table 5 Prevalence of child maltreatment by socio-demographic variables

\begin{tabular}{|c|c|c|c|c|c|c|}
\hline & $\mathrm{N}$ total & $\begin{array}{l}\text { Emotional abuse } \\
\mathrm{N}(\%)\end{array}$ & $\begin{array}{l}\text { Physical abuse } \\
\text { N (\%) }\end{array}$ & $\begin{array}{l}\text { Sexual abuse } \\
\mathrm{N}(\%)\end{array}$ & $\begin{array}{l}\text { Emotional neglect } \\
\mathrm{N}(\%)\end{array}$ & $\begin{array}{l}\text { Physical neglect } \\
\mathrm{N}(\%)\end{array}$ \\
\hline \multicolumn{7}{|l|}{ Employed/unemployed } \\
\hline Employed & 2332 & $144(6.1)$ & $150(6.4)$ & $172(7.3)$ & $304(13.0)$ & $520(22.1)$ \\
\hline Unemployed & 127 & $19(14.6)$ & $17(13.2)$ & $17(13.1)$ & $26(20.0)$ & $38(29.7)$ \\
\hline $\mathrm{Chi}^{2}$ & & $14.35^{* *}$ & $8.98^{*}$ & $5.78^{*}$ & $5.30^{*}$ & $3.97^{*}$ \\
\hline \multicolumn{7}{|l|}{ Education } \\
\hline Did not graduate school & 55 & $10(18.2)$ & $11(20.0)$ & $8(14.5)$ & $14(25.5)$ & $17(30.9)$ \\
\hline Graduated school & 2103 & $136(6.5)$ & $148(7.0)$ & $164(7.8)$ & $299(14.2)$ & $507(24.1)$ \\
\hline University degree & 247 & $15(6.1)$ & $4(1.6)$ & $15(6.0)$ & $16(6.5)$ & $34(13.8)$ \\
\hline $\mathrm{Chi}^{2}$ & & $11.95^{*}$ & $25.87^{* *}$ & 4.55 & $17.80^{* *}$ & $14.85^{*}$ \\
\hline \multicolumn{7}{|l|}{ Equivalence income } \\
\hline$<1250 € /$ month & 544 & $47(8.6)$ & $43(7.9)$ & $46(8.5)$ & $91(16.7)$ & $152(27.9)$ \\
\hline $1250-2500 € /$ month & 1469 & $75(5.1)$ & $80(5.4)$ & $94(6.4)$ & $168(11.4)$ & $311(21.2)$ \\
\hline$>2500 € /$ month & 392 & $17(4.3)$ & $16(4.1)$ & $26(6.6)$ & $47(12)$ & $62(15.8)$ \\
\hline $\mathrm{Chi}^{2}$ & & $10.94^{* *}$ & $6.94^{*}$ & 2.7 & $10.2^{* *}$ & $20.7^{* * *}$ \\
\hline
\end{tabular}

${ }^{*} p<.05,{ }^{* *} p<.001$ 
Female gender was found to be a significant predictor for sexual and emotional abuse. Especially the finding on sexual abuse is in line with findings from meta-analyses that report a preponderance for female gender [3, 1012], and do not report a skewed distribution for the other types of maltreatment [15-17].

\section{Co-occurrence of different types of maltreatment}

As literature demonstrates, different types of child maltreatment are interrelated and the co-occurrence of different types of maltreatment is rather the rule than the exception [34]. Due to observing a population based sample, the rates of co-occurrences of different types of maltreatment were lower than reported from clinical samples [35]. Additionally, the present study included a high number of participants reporting physical neglect without having experienced any other type of maltreatment. However, results show that both types of neglect (physical and emotional) often co-occur, as well as combinations with other types of abuse, such as emotional and physical abuse.

\section{Limitations}

The retrospective assessment of child maltreatment may always be affected by different biases e.g. recollection biases. The random rout approach systematically excludes people that are currently residing in institutions. Therefore certain high risk-samples such as residents of child welfare institutions with a high prevalence of sexual abuse [36] may have been underrepresented in the current sample.

\section{Conclusions}

Child maltreatment, especially physical neglect, is common among the general population of Germany. Physical neglect is highly prevalent in the (post) World War II generation and steadily declines towards the youngest age group. In general, experiences of child maltreatment are associated with a lower sociodemographic status. Women are more likely to report at least moderate levels of emotional and sexual abuse than men. Different types of maltreatment, especially physical and emotional neglect, seem to co-occur frequently.

\section{Authors' contributions}

AW and RB analyzed and interpreted the data. RB carefully read the manuscript and provided a language editing. PLP, JMF and EB were involved in planning the study, drafting the manuscript and language editing. All authors read and approved the final manuscript.

\section{Author details}

1 Department of Child and Adolescent Psychiatry/Psychotherapy, University of Ulm, Steinhövelstr. 5, 89073 Ulm, Germany. ${ }^{2}$ Department of Psychosomatic Medicine and Psychotherapy, University Medical Center of Johannes Gutenberg University Mainz, Mainz, Germany. ${ }^{3}$ Department of Medical Psychology and Medical Sociology, University of Leipzig, Leipzig, Germany.

\section{Competing interests}

$A W, R B, E B$ state that they have no competing interests.

JMF has received research funding from the EU, DFG (German Research Foundation), BMG (Federal Ministry of Health), BMBF (Federal Ministry of Education and Research), BMFSFJ (Federal Ministry of Family, Senior Citizens, Women and Youth), German armed forces, several state ministries of social affairs, State Foundation Baden-Württemberg, Volkswagen Foundation, European Academy, Pontifical Gregorian University, RAZ, CJD, Caritas, Diocese of Rottenburg-Stuttgart. Moreover, he received travel grants, honoraria and sponsoring for conferences and medical educational purposes from DFG, AACAP, NIMH/NIH, EU, Pro Helvetia, Janssen-Cilag (J\&), Shire, several universities, professional associations, political foundations, and German federal and state ministries during the last 5 years. Every grant and every honorarium has to be declared to the law office of the University Hospital Ulm. Professor Fegert holds no stocks of pharmaceutical companies.

PLP has received research funding from the Bundesinstitut für Arzneimittel und Medizinprodukte, BMBF (Federal Ministry of Education and Research), VWFoundation, Baden-Württemberg Stiftung, Lundbeck, Servier. Professor Plener holds no stocks of pharmaceutical companies.

\section{Availability of data and materials}

The datasets generated and/or analyzed during the current study are not publicly available due to ownership of the data but are available from the corresponding author on reasonable request.

\section{Consent for publication}

Not applicable.

\section{Ethics approval and consent to participate}

The study was conducted in accordance with the Declaration of Helsinki, and fulfilled the ethical guidelines of the International Code of Marketing and Social Research Practice of the International Chamber of Commerce and of the European Society of Opinion and Marketing Research. Prior to being carried out, it was approved by the Ethics Committee of the Medical Faculty of the University of Leipzig. All participants were informed about the study and the possibility of a later withdrawal of their consent. For participants under the age of 18 years additionally an adult was informed about the participation.

Funding

Not applicable.

\section{Publisher's Note}

Springer Nature remains neutral with regard to jurisdictional claims in published maps and institutional affiliations.

Received: 20 June 2017 Accepted: 29 August 2017

Published online: 29 September 2017

\section{References}

1. Gilbert R, Widom CS, Browne K, Fergusson DM, Webb E, Janson S. Burden and consequences of child maltreatment in high-income countries. Lancet. 2009;373:68-81.

2. Fegert JM, Stotzel M. Child protection: a universal concern and a permanent challenge in the field of child and adolescent mental health. Child Adolesc Psychiatry Ment Health. 2016;10:18.

3. Jud A, Fegert JM, Finkelhor D. On the incidence and prevalence of child maltreatment: a research agenda. Child Adolesc Psychiatry Ment Health. 2016;10:17

4. Weber S, Jud A, Landolt MA. Quality of life in maltreated children and adult survivors of child maltreatment: a systematic review. Qual Life Res. 2016;25(2):237-55. doi:10.1007/s11136-015-1085-5.

5. De Bellis MD. Developmental traumatology: the psychobiological development of maltreated children and its implications for research, treatment, and policy. Dev Psychopathol. 2001;13:539-64.

6. Norman RE, Byambaa M, De R, Butchart A, Scott J, Vos T. The longterm health consequences of child physical abuse, emotional abuse, 
and neglect: a systematic review and meta-analysis. PLoS Med. 2012;9:e1001349

7. Habetha S, Bleich S, Weidenhammer J, Fegert JM. A prevalence-based approach to societal costs occurring in consequence of child abuse and neglect. Child Adolesc Psychiatry Ment Health. 2012;6:35.

8. Fang X, Brown DS, Florence CS, Mercy JA. The economic burden of child maltreatment in the United States and implications for prevention. Child Abuse Negl. 2012;36:156-65.

9. Gilbert R, Fluke J, O'Donnell M, Gonzalez-Izquierdo A, Brownell M, Gulliver $P$, et al. Child maltreatment: variation in trends and policies in six developed countries. Lancet. 2012;379:758-72.

10. Sethi D, Bellis M, Hughes K, Gilbert R, Mitis F, Galea G. European report on preventing child maltreatment. Copenhagen: World Health Organisation Regional Office for Europe; 2013.

11. Stoltenborgh $M$, van ljzendoorn MH, Euser EM, Bakermans-Kranenburg MJ. A global perspective on child sexual abuse: meta-analysis of prevalence around the world. Child Maltreat. 2011;16:79-101.

12. Pereda N, Guilera G, Forns M, Gomez-Benito J. The international epidemiology of child sexual abuse: a continuation of Finkelhor (1994). Child Abuse Negl. 2009:33:331-42.

13. Barth J, Bermetz L, Heim E, Trelle S, Tonia T. The current prevalence of child sexual abuse worldwide: a systematic review and meta-analysis. Int J Public Health. 2013;58:469-83.

14. McSherry D. Understanding and addressing the "neglect of neglect": why are we making a mole-hill out of a mountain? Child Abuse Negl. 2007;31:607-14.

15. Stoltenborgh M, Bakermans-Kranenburg MJ, van ljzendoorn MH. The neglect of child neglect: a meta-analytic review of the prevalence of neglect. Soc Psychiatry Psychiatr Epidemiol. 2013;48:345-55.

16. Stoltenborgh M, Bakermans-Kranenburg MJ, van ljzendoorn MH, Alink LR. Cultural-geographical differences in the occurrence of child physical abuse? A meta-analysis of global prevalence. Int J Psychol. 2013;48:81-94.

17. Stoltenborgh M, Bakermans-Kranenburg MJ, Alink LR, van ljzendoorn MH. The universality of childhood emotional abuse: a meta-analysis of worldwide prevalence. J Aggress Maltreat Trauma. 2012;21:870-90.

18. Stadler L, Bieneck S, Wetzels P. Viktimisierung durch sexuellen Kindesmissbrauch: befunde national-repräsentativer Dunkelfeldforschung zu Entwicklungstrends in Deutschland. Praxis der Rechtspsychologie. 2012;22:190-220.

19. Wetzels P. Zur Epidemiologie physischer und sexueller Gewalterfahrungen in der Kindheit: Ergebnisse einer repräsentativen retrospektiven Prävalenzstudie für die BRD. Hannover: Kriminilogisches Forschungsinstitut Niedersachsen; 1997.

20. Stadler L, Bieneck S, Pfeiffer C. Repräsentativbefragung Sexueller Missbrauch 2011: Forschungsbericht Nr. 118. Hanover: Kriminologisches Forschungsinstitut Niedersachsen; 2012

21. Klinitzke G, Romppel M, Hauser W, Brahler E, Glaesmer H. The German Version of the Childhood Trauma Questionnaire (CTQ): psychometric characteristics in a representative sample of the general population. Psychother Psychosom Med Psychol. 2012;62:47-51.
22. Häuser W, Schmutzer G, Brähler E, Glaesmer H. Misshandlung in Kindheit und Jugend: ergebnisse einer Umfrage in einer repräsentativen Stichprobe der deutschen Bevölkerung. Deutsches Ärzteblatt. 2011;108:287-311.

23. Quidé Y, Ong XH, Mohnke S, Schnell K, Walter H, Carr VJ, Green MJ. Childhood trauma-related alterations in brain function during a Theoryof-Mind task in schizophrenia. Schizophr Res. 2017. doi:10.1016/j. schres.2017.02.012.

24. Dannlowski U, Stuhrmann A, Beutelmann V, Zwanzger P, Lenzen T, Grotegerd D, et al. Limbic scars: long-term consequences of childhood maltreatment revealed by functional and structural magnetic resonance imaging. Biol Psychiatry. 2012;71:286-93.

25. Glaesmer H. Assessing childhood maltreatment on the population leve in Germany: findings and methodological challenges. Child Adolesc Psychiatry Ment Health. 2016;10:15.

26. Hovdestad W, Campeau A, Potter D, Tonmyr L. A systematic review of childhood maltreatment assessments in population-representative surveys since 1990. PLoS ONE. 2015;10:e0123366.

27. OECD. OECD framework for statistics on the distribution of household income, consumption and wealth. Paris: OECD publishing; 2013.

28. Wingenfeld K, Spitzer C, Mensebach C, Grabe HJ, Hill A, Gast U, et al. The German version of the Childhood Trauma Questionnaire (CTQ): preliminary psychometric properties. Psychother Psychosom Med Psychol. 2010;60:e13.

29. Bernstein DP, Stein JA, Newcomb MD, Walker E, Pogge D, Ahluvalia T, et al. Development and validation of a brief screening version of the Childhood Trauma Questionnaire. Child Abuse Negl. 2003;27:169-90.

30. Rassenhofer M, Zimmer A, Sprober N, Fegert JM. Child sexual abuse in the Roman Catholic Church in Germany: comparison of victim-impact data collected through church-sponsored and government-sponsored programs. Child Abuse Negl. 2015;40:60-7.

31. US Department of Health and Human Services. Child maltreatment 2014. Washington: US Government Printing Office; 2015.

32. Bussmann KD, Erthak C, Schroth A. Effects of banning corporal punishment in Europe. In: Durrant JE, Smith AB, editors. Global pathways to abolishing physical punishment. Abingdon: Routledge; 2011. p. 299-322.

33. Bussmann KD. Familiengewalt report. 2005.

34. Herrenkohl RC, Herrenkohl TI. Assessing a child's experience of multiple maltreatment types: some unfinished business. J Fam Violence. 2009;24:485.

35. Witt A, Munzer A, Ganser HG, Fegert JM, Goldbeck L, Plener PL. Experience by children and adolescents of more than one type of maltreatment: association of different classes of maltreatment profiles with clinical outcome variables. Child Abuse Negl. 2016:57:1-11.

36. Allroggen M, Rau T, Ohlert J, Fegert JM. Lifetime prevalence and incidence of sexual victimization of adolescents in institutional care. Child Abuse Negl. 2017;66:23-30. doi:10.1016/j.chiabu.2017.02.015.

\section{Submit your next manuscript to BioMed Central and we will help you at every step:}

- We accept pre-submission inquiries

- Our selector tool helps you to find the most relevant journal

- We provide round the clock customer support

- Convenient online submission

- Thorough peer review

- Inclusion in PubMed and all major indexing services

- Maximum visibility for your research

Submit your manuscript at www.biomedcentral.com/submit 